\title{
The biogeography of
} introgression in the critically endangered African monkey

\section{Rungwecebus kipunji}

Trina E. Roberts ${ }^{1,2, *}$, Tim R. B. Davenport ${ }^{3}$, Kyndall B. P. Hildebrandt ${ }^{1,4}$, Trevor Jones ${ }^{5,6}$, William T. Stanley ${ }^{7}$, Eric J. Sargis 8,9 and Link E. Olson ${ }^{1,4}$

${ }^{1}$ Department of Mammalogy, University of Alaska Museum, Fairbanks, AK 99775, USA

${ }^{2}$ National Evolutionary Synthesis Center, Durham, NC 27705, USA ${ }^{3}$ Wildlife Conservation Society, Tanzania Program, Mbeya, Tanzania ${ }^{4}$ Institute of Arctic Biology, University of Alaska Fairbanks, Fairbanks, AK 99775, USA

${ }^{5}$ Animal and Environmental Research Group, Department of Life Sciences, Anglia Ruskin University, Cambridge CB1 1PT, UK

${ }^{6}$ Udzungwa Ecological Monitoring Centre, Mang'ula, Tanzania ${ }^{7}$ Department of Zoology, Field Museum of Natural History, Chicago, IL 60605, USA

${ }^{8}$ Department of Anthropology, Yale University, New Haven, CT 06520-8277, USA

${ }^{9}$ Division of Vertebrate Zoology, Peabody Museum of Natural History, Yale University, New Haven, CT 06520-8118, USA

*Author for correspondence (trina.roberts@nescent.org).

In the four years since its original description, the taxonomy of the kipunji (Rungwecebus kipunji), a geographically restricted and critically endangered African monkey, has been the subject of much debate, and recent research suggesting that the first voucher specimen of Rungwecebus has baboon mitochondrial DNA has intensified the controversy. We show that Rungwecebus from a second region of Tanzania has a distinct mitochondrial haplotype that is basal to a clade containing all Papio species and the original Rungwecebus voucher, supporting the placement of Rungwecebus as the sister taxon of Papio and its status as a separate genus. We suggest that the Rungwecebus population in the Southern Highlands has experienced geographically localized mitochondrial DNA introgression from Papio, while the Ndundulu population retains the true Rungwecebus mitochondrial genome.

Keywords: baboons; hybridization; kipunji; Papio; Rungwecebus; Tanzania

\section{INTRODUCTION}

The significance of introgressive hybridization in the evolution of wild populations is poorly understood. In cercopithecine primates, hybridization and persistent introgression have been reported in macaques (Macaca; e.g. Kanthaswamy et al. 2008), guenons (Cercopithecus; e.g. Tutin 1999; Detwiler 2002) and baboons (Papio; e.g. Phillips-Conroy \& Jolly 1986;

Samuels \& Altmann 1986; Alberts \& Altmann 2001; Zinner et al. 2009b), as well as between baboons and geladas (Theropithecus; Dunbar \& Dunbar 1974; Jolly et al. 1997), suggesting that reproductive isolating mechanisms may be weak or absent. The long-term consequences of hybridization vary widely and depend largely on natural selection, population genetics, demography, anthropogenic influences and the complex dynamics of gene flow among populations. In this study, we report new information about the role of introgression in the evolutionary history of the kipunji (Rungwecebus kipunji), a unique, geographically restricted, and 'critically endangered' African monkey (Davenport \& Jones 2008).

The kipunji was originally described as a new species of mangabey, Lophocebus kipunji (Jones et al. 2005), on the basis of external morphology and behaviour. When a dead subadult from the type locality, Mt Rungwe in Tanzania's Southern Highlands, became available, Davenport et al. (2006) used genetic data to show that this classification was incorrect. They erected a new genus, Rungwecebus, recognizing the kipunji's phylogenetic placement - sister to Papio in their analyses - and its lack of the diagnostic morphology of baboons. Olson et al. (2008) confirmed this phylogenetic result with additional molecular markers, and Singleton's (2009) geometric morphometric analysis showed that Rungwecebus is morphologically distinct from both Lophocebus and Papio. Continuing ecological and behavioral study has also improved our understanding of the kipunji's biology and distribution (e.g. Davenport \& Jones 2008; Davenport et al. 2008).

Two recent studies with broader taxonomic and geographical representation for Papio (Burrell et al. 2009; Zinner et al. 2009a) have renewed debate about the evolutionary history of Rungwecebus. Both showed that the mitochondrial haplotype from the original Rungwecebus voucher specimen is nested within Papio, in which introgression and mitochondrial polyphyly seem to be common (Zinner et al. 2009b). Zinner et al. (2009a) suggested that Rungwecebus is sister to Papio with past introgressive hybridization, as previously proposed by Olson et al. (2008), while Burrell et al. (2009) suggested that Rungwecebus originated via hybridization between Lophocebus and Papio. However, the genetic information for Rungwecebus has never been geographically complete. Rungwecebus is known from two populations in Tanzania (figure 1)-one in the Southern Highlands (Mt Rungwe and the adjacent Livingstone Forest in Kitulo National Park), and the other $350 \mathrm{~km}$ to the northeast in Ndundulu Forest, within the Kilombero Nature Reserve in the Udzungwa Mountains (Davenport et al. 2008). The original voucher specimen, which was the source of all previous Rungwecebus sequences, came from Mt Rungwe; no genetic material from the Udzungwas has been available until now. Here, we add the first DNA sequences of Rungwecebus from Ndundulu, as well as two additional sequences from Mt Rungwe-Kitulo.

\section{MATERIAL AND METHODS}

We extracted and sequenced mtDNA from six kipunji stool samples from the Ndundulu population and two additional fresh tissue specimens from the Southern Highlands - one from Mt Rungwe and one from Livingstone Forest-using standard methods for PCR 


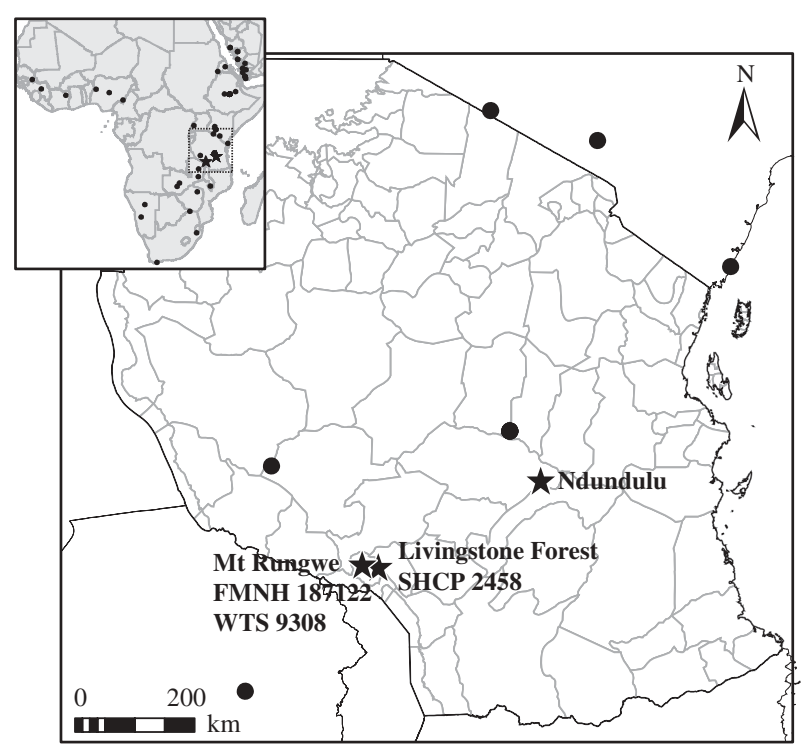

Figure 1. Locations in Tanzania and across Africa (inset) for Papio and Rungwecebus samples. Filled circle, Papio; filled star, Rungewecebus.

amplification, sequencing, and fragment assembly (table 1; figure 1). Based on the collection locations, dates and conditions, we are very confident that the sequenced samples come from six different individuals. We sequenced four mtDNA fragments and aligned them to sequences from GenBank (see the electronic supplementary material, table S1): (i) $600 \mathrm{bp}$ of the cytochrome oxidase I (COI) gene; (ii) $500 \mathrm{bp}$ of the cytochrome oxidase II (COII) gene; (iii) $408 \mathrm{bp}$ of the $12 \mathrm{~S}$ rRNA gene; and (iv) $897 \mathrm{bp}$ spanning part of NADH dehydrogenase subunit 4 (ND4), 3 tRNAs, and part of NADH dehydrogenase subunit 5 (ND5). We performed phylogenetic analyses of the individual fragments and a combined dataset of COI, COII, and $12 \mathrm{~S}$ with reduced taxon sampling. Details of specimen collection and laboratory and analytical methods are in the electronic supplementary material.

\section{RESULTS AND DISCUSSION}

The six stool samples share a single haplotype for all sequenced fragments. Phylogenetic analyses of the individual fragments and the combined data are consistent with respect to the placement of Rungwecebus (figure 2 and see the electronic supplementary material, figures S1-S7). The original sample (FMNH 187122) and the two new samples from Mt Rungwe-Kitulo (SHCP 2458 and WTS 9308) cluster together, within the extant mitochondrial diversity in Papio. However, the Ndundulu kipunji haplotype is strongly supported as the sister lineage to this Papio-Rungwecebus clade. The mean uncorrected genetic distance between the Ndundulu and Mt Rungwe-Kitulo kipunji haplotypes is 4.81 per cent (table 2). The proximity between Mt RungweKitulo and Papio haplotypes is unlikely to be owing to incomplete lineage sorting, which results in shared haplotype lineages that are old relative to species divergences. The disparity in genetic diversity between the two kipunji populations suggests differing effective population sizes or demographic histories, although stronger inference from diversity statistics will require larger sample sizes.

Overall, our results, together with previous observations of morphological distinctiveness, indicate that Rungwecebus is the sister lineage of Papio but has

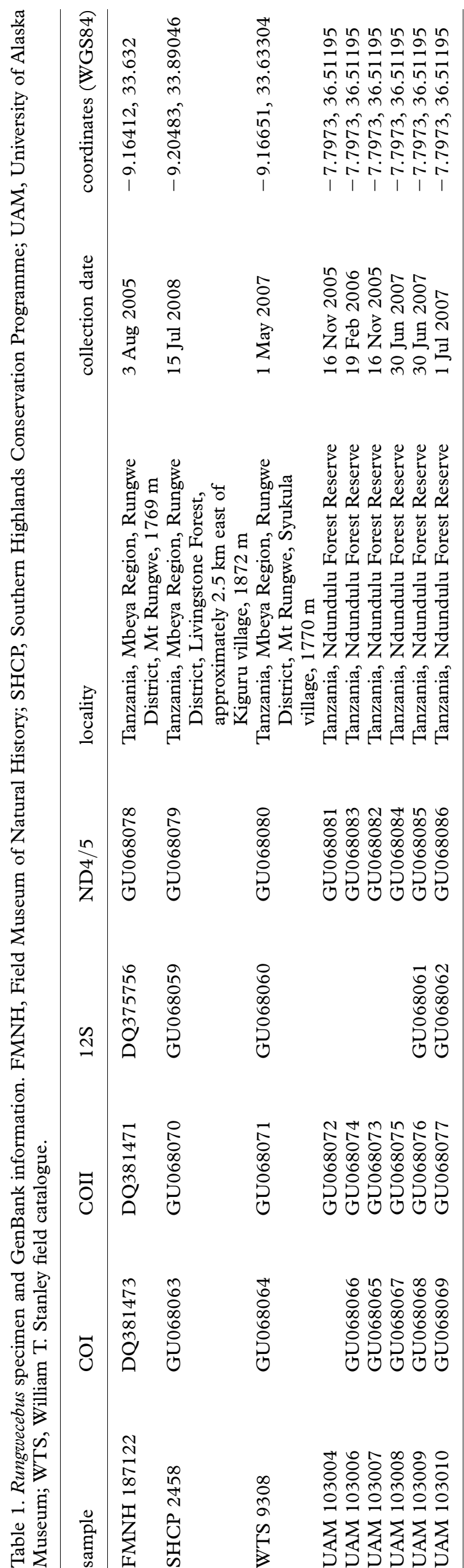




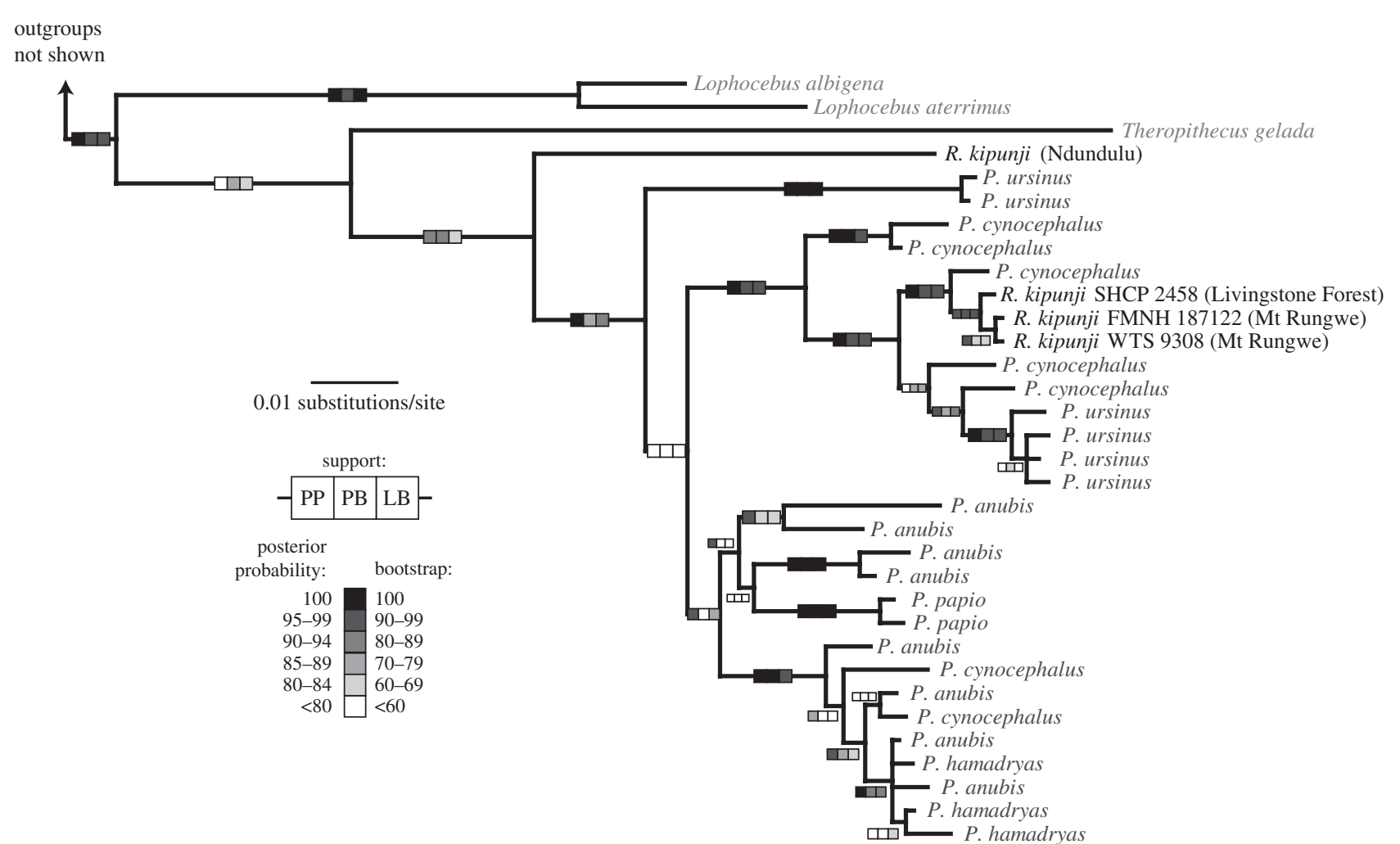

Figure 2. Bayesian 50 per cent consensus tree for combined data. Shaded boxes show posterior probability (PP), parsimony bootstrap (PB), and likelihood bootstrap (LB) support. Outgroups not shown.

Table 2. Uncorrected pairwise genetic distance between populations or species. Above diagonal, minimum; below diagonal, mean; diagonal, nucleotide diversity.

\begin{tabular}{|c|c|c|c|c|c|c|c|c|c|}
\hline & $\begin{array}{l}\text { Rungwecebus } \\
\text { Ndundulu }\end{array}$ & $\begin{array}{l}\text { Rungwecebus } \\
\text { Mt Rungwe- } \\
\text { Kitulo }\end{array}$ & $\begin{array}{l}\text { Papio } \\
\text { cynocephalus }\end{array}$ & $\begin{array}{l}\text { Papio } \\
\text { anubis }\end{array}$ & $\begin{array}{l}\text { Papio } \\
\text { papio }\end{array}$ & $\begin{array}{l}\text { Papio } \\
\text { ursinus }\end{array}$ & $\begin{array}{l}\text { Papio } \\
\text { hamadryas }\end{array}$ & Theropithecus & Lophocebus \\
\hline $\begin{array}{l}\text { Rungwecebus } \\
\text { Ndundulu }\end{array}$ & 0.0000 & 0.0481 & 0.0426 & 0.0440 & 0.0474 & 0.0467 & 0.0440 & 0.0735 & 0.0639 \\
\hline $\begin{array}{l}\text { Rungwecebus } \\
\text { Mt Rungwe- } \\
\text { Kitulo }\end{array}$ & 0.0481 & 0.0009 & 0.0055 & 0.0302 & 0.0309 & 0.0130 & 0.0316 & 0.0680 & 0.0659 \\
\hline $\begin{array}{l}\text { Papio } \\
\quad \text { cynocephalus }\end{array}$ & 0.0457 & 0.0203 & 0.0247 & 0.0027 & 0.0254 & 0.0076 & 0.0041 & 0.0639 & 0.0639 \\
\hline Papio anubis & 0.0468 & 0.0328 & 0.0282 & 0.0197 & 0.0185 & 0.0323 & 0.0007 & 0.0646 & 0.0625 \\
\hline Papio papio & 0.0484 & 0.0322 & 0.0296 & 0.0242 & 0.0021 & 0.0330 & 0.0247 & 0.0646 & 0.0660 \\
\hline Papio ursinus & 0.0488 & 0.0226 & 0.0286 & 0.0374 & 0.0348 & 0.0237 & 0.0350 & 0.0687 & 0.0639 \\
\hline $\begin{array}{l}\text { Papio } \\
\text { hamadryas }\end{array}$ & 0.0453 & 0.0330 & 0.0258 & 0.0154 & 0.0267 & 0.0388 & 0.0037 & 0.0680 & 0.0666 \\
\hline Theropithecus & 0.0735 & 0.0680 & 0.0668 & 0.0669 & 0.0656 & 0.0701 & 0.0696 & XXXX & 0.0762 \\
\hline Lophocebus & 0.0656 & 0.0694 & 0.0706 & 0.0684 & 0.0684 & 0.0706 & 0.0704 & 0.0776 & XXXX \\
\hline
\end{tabular}

experienced geographically localized introgressive hybridization in the Southern Highlands, introducing Papio DNA long after the divergence between these two genera. We base our conclusion on samples from two different populations across the known range of the kipunji in the Southern Highlands, both of which contain apparently introgressed haplotypes. We consider the Ndundulu haplotype to represent the true (non-introgressed) Rungwecebus mitochondrial genome, although rigorously testing this will require both additional genetic data and morphological corroboration using voucher specimens.
The presence of introgressed Papio haplotypes in one kipunji population implies past (and perhaps present) contact between Rungwecebus and baboons. Both Rungwecebus populations live in forest near Papio cynocephalus, which inhabits the dry bush adjacent to Ndundulu as well as open habitats and farmland adjacent to Mt Rungwe and Kitulo. The two species are separated primarily by habitat preference, but P. cynocephalus is known to enter forest and Rungwecebus has been observed on the ground in recently cultivated areas outside the forest (Davenport \& Jones 2008). The frequency with which kipunji and baboons have 
encountered each other may vary between the two areas, and may have changed over time as a result of local cycles of climate change, wildfires, and other disturbance. Anthropogenic factors may also be important in determining very recent interactions; being persistent crop-raiders and legally classified in Tanzania as 'vermin,' baboons are now increasingly rare in the areas of high human density that surround the Mt Rungwe forest.

It is unsurprising that the Ndundulu and $\mathrm{Mt}$ Rungwe-Kitulo kipunji populations may have different evolutionary histories. As well as having local differences in habitat and ecology, the two areas are separated by $350 \mathrm{~km}$ of non-forest habitat, preventing any gene flow between them. Indeed, the Udzungwas are considered the southernmost range of the Eastern Arc Mountains (Lovett \& Wasser 1993), which until recently were thought to be biogeographically distinct from the Southern Highlands. The large number of endemic taxa in each region suggests long-term isolation, as does the fact that some appear to be of ancient origin and have geographically distant sister taxa (Dinesen et al. 1994; Stanley et al. 2005). In the past few years, however, the discovery in $\mathrm{Mt}$ Rungwe, Kitulo and other Southern Highlands sites of a wide range of vertebrates previously thought to be Eastern Arc endemics has cast doubt on the biogeographic distinction between these two areas (Davenport 2004; Carleton \& Stanley 2005). It now seems probable that they were once linked by a forest corridor that has since disappeared, isolating populations of forest-dependent taxa such as the kipunji.

Further understanding of the evolutionary history of Rungwecebus and the differences between the two populations will require adult specimens from both $\mathrm{Mt}$ Rungwe-Kitulo and Ndundulu suitable for morphological and genetic research. The Livingstone Forest specimen (SHCP 2458) possesses all the diagnostic features of Rungwecebus (i.e. erect crest of hair on the crown, black eyelids, long tail with light tip, and lack of a long rostrum and mandibular fossae). Unfortunately, this specimen, though an older individual than the original voucher, is another subadult, and the osteomorphology of adult Rungwecebus will remain a matter of conjecture until adult specimens become available.

The original description of the kipunji in 2005 was trumpeted as an example of how little we still know about biodiversity and additional research has accentuated this point. The two existing Rungwecebus populations have experienced a complex, idiosyncratic history of independent divergence and subsequent hybridization with a closely related genus, probably dependent on an intricate and dynamic background of population connectivity and demography. Our ongoing research on additional aspects of the biology of this unique and critically endangered genus will enhance our understanding of hybridization, evolution, and biogeography in a region of Africa that remains surprisingly poorly known.

The Tanzania Wildlife Research Institute and Tanzania Commission for Science and Technology and the Wildlife Division granted research permits to W.T.S., T.J. and T.R.B.D.
This research was supported in part by NSF grant DEB-0542725/0542532 to L.E.O. and E.J.S. T.R.B.D. and T.J. were supported by the Wildlife Conservation Society. T.E.R. was supported in part by a NESCent postdoctoral fellowship (NSF EF-0423641). Claire Bracebridge and Noah Mpunga provided aid in securing and preparing specimens. DNA sequencing was conducted in the UAF IAB Core Facility for Nucleic Acid Analysis with support from NSF EPSCoR grant EPS-0346770.

Alberts, S. C. \& Altmann, J. 2001 Immigration and hybridization patterns of yellow and anubis baboons in and around Amboseli, Kenya. Am. F. Primatol. 53, 139-154. (doi:10.1002/ajp.1)

Burrell, A. S., Jolly, C. J., Tosi, A. J. \& Disotell, T. R. 2009 Mitochondrial evidence for the hybrid origin of the kipuni, Rungwecebus kipunji (Primates: Papionini). Mol. Phylogenet. Evol. 51, 340-348. (doi:10.1016/j.ympev.2009.02.004)

Carleton, M. D. \& Stanley, W. T. 2005 Review of the Hylomyscus denniae complex (Rodentia: Muridae) in Tanzania, with a description of a new species. Proc. Biol. Soc. Wash. 118, 619-646. (doi:10.2988/0006-324X(2005) 118[619:ROTHDC]2.0.CO;2)

Davenport, T. R. B. 2004 Where the arcs meet the rift: biogeography, outliers, and conservation in Tanzania's Southern Highlands. Soc. Cons. Biol. Abstr. 48, 20.

Davenport, T. R. B. \& Jones, T. 2008 Rungwecebus kipunji. In 2008 IUCN red list of threatened species. Version 2009.1 (IUCN 2009) (http://www.iucnredlist.org/ details/136791). Accessed on 16 October 2009.

Davenport, T. R. B., Stanley, W. T., Sargis, E. J., De Luca, D. W., Mpunga, N. E., Machaga, S. J. \& Olson, L. E. 2006 A new genus of African monkey, Rungwecebus: morphology, ecology, and molecular phylogenetics. Science 312, 1378-1381. (doi:10.1126/science.1125631)

Davenport, T. R. B., De Luca, D. W., Jones, T., Mpunga, N. E., Machaga, S. J., Kitegile, A. \& Phillipps, G. P. 2008 The critically endangered kipunji Rungwecebus kipunji of southern Tanzania: first census and conservation status assessment. Oryx 42, 352-359.

Detwiler, K. M. 2002 Hybridization between red-tailed monkeys (Cercopithecus ascanius) and blue monkeys (C. mitis) in East African forests. In The Guenons: diversity and adaptation in African monkeys (eds M. E. Glenn \& M. Cords), pp. 79-98. New York, NY: Springer.

Dinesen, L., Lehmberg, T., Svendsen, T. O., Hansen, L. A. \& Fjeldså, J. 1994 A new genus and species of perdicine bird (Phasianidae, Perdicini) from Tanzania: a relict form with Indo-Malayan affinities. Ibis 136, 3-11. (doi:10.1111/ j.1474-919X.1994.tb08125.x)

Dunbar, R. I. M. \& Dunbar, P. 1974 On hybridization between Theropithecus gelada and Papio anubis in the wild. F. Hum. Evol. 3, 187-192. (doi:10.1016/00472484(74)90176-6)

Jolly, C. J., Woolley-Barker, T., Beyene, S., Disotell, T. R. \& Phillips-Conroy, J. E. 1997 Intergeneric hybrid baboons. Int. f. Primatol. 18, 597-627. (doi:10.1023/ A:1026367307470)

Jones, T., Ehardt, C. L., Butynski, T. M., Davenport, T. R. B., Mpunga, N. E., Machaga, S. J. \& De Luca, D. W. 2005 The highland mangabey Lophocebus kipunji: a new species of African monkey. Science 308, 1161-1164. (doi:10.1126/science.1109191)

Kanthaswamy, S., Satkoski, J., George, D., Kou, A., Erickson, B. J. \& Smith, D. G. 2008 Hybridization and stratification of nuclear genetic variation in Macaca mulatta and M. fascicularis. Int. F. Primatol. 29, 1295-1311. (doi:10.1007/s10764-008-9295-0) 
Lovett, J. C. \& Wasser, S. K. 1993 Biogeography and ecology of the rain forests of Eastern Africa. Cambridge, UK: Cambridge University Press.

Olson, L. E., Sargis, E. J., Stanley, W. T., Hildebrandt, K. B. P. \& Davenport, T. R. B. 2008 Additional molecular evidence strongly supports the distinction between the recently described African primate Rungwecebus kipunji (Cercopithecidae, Papionini) and Lophocebus. Mol. Phylogenet. Evol. 48, 789-794. (doi:10.1016/j.ympev. 2008.04.031)

Phillips-Conroy, J. E. \& Jolly, C. J. 1986 Changes in the structure of the baboon hybrid zone in the Awash National Park, Ethiopia. Am. F. Phys. Anthropol. 71, 337-350. (doi:10.1002/ajpa.1330710309)

Samuels, A. \& Altmann, J. 1986 Immigration of a Papio anubis male into a group of Papio cynocephalus baboons and evidence for an anubis-cynocephalus hybrid zone in Amboseli, Kenya. Int. F. Primatol. 7, 131-138. (doi:10. 1007/BF02692314)
Singleton, M. 2009 The phenetic affinities of Rungwecebus kipunji. f. Hum. Evol. 56, 25-42. (doi:10.1016/j.jhevol. 2008.07.012)

Stanley, W. T., Rogers, M. A. \& Hutterer, R. 2005 A new species of Congosorex from the Eastern Arc Mountains, Tanzania, with significant biogeographical implications. f. Zool. 265, 269-280. (doi:10.1017/ S0952836904006314)

Tutin, C. E. G. 1999 Fragmented living: behavioural ecology of primates in a forest fragment in the Lopé Reserve, Gabon. Primates 40, 249-265. (doi:10.1007/ BF02557714)

Zinner, D., Arnold, M. L. \& Roos, C. $2009 a$ Is the new primate genus Rungwecebus a baboon? PLoS ONE 4, e4859. (doi:10.1371/journal.pone.0004859)

Zinner, D., Groeneveld, L. F., Keller, C. \& Roos, C. $2009 b$ Mitochondrial phylogeography of baboons (Papio spp.): indication for introgressive hybridization? BMC Evol. Biol. 9, 83. (doi:10.1186/1471-2148-9-83) 